\title{
Tooth Crown Morphology in Turner and Klinefelter Syndrome Individuals from a Croatian Sample
}

\section{Morfologija krune zuba u osoba s Turnerovim i Klinefelterovim sindromom iz hrvatskog uzorka}

\author{
${ }^{1}$ Eckerd College, Department of Anthropology, $420054^{\text {th }}$ Ave. S. St. Petersburg, FL 33711, USA, \\ Zavod za antropologiju Fakulteta Eckerd, St. Petersburg, Florida, SAD \\ 2 University of Zagreb School of Dental Medicine, Department of Dental Anthropology, Zagreb, Croatia, \\ Zavod za dentalnu antropologiju Stomatološkog fakulteta Sveučilišta u Zagrebu, Hrvatska \\ ${ }^{3}$ Department of Dental Medicine, University Hospital Centre Zagreb, Croatia \\ Klinika za stomatologiju Kliničkoga bolničkog centra Zagreb, Hrvatska \\ ${ }^{4}$ Croatian Dental Chamber, Zagreb, Croatia \\ Hrvatska komora dentalne medicine, Zagreb, Hrvatska \\ ${ }^{5}$ Croatian Academy of Medical Sciences, Zagreb, Croatia \\ Akademija medicinskih znanosti Hrvatske, Zagreb, Hrvatska \\ 6 University of Nevada, Reno, Department of Anthropology, 1664 N. Virginia St., Reno, NV USA \\ Zavod za antropologiju Sveučilišta u Nevadi, Reno, Nevada, SAD
}

\section{Abstract}

Objective: Turner syndrome (TS) and Klinefelter syndrome (KS) represent the two most common $\mathrm{X}$ chromosome aneuploidies, each associated with systemic disruptions to growth and development. Effects of these conditions on tooth crown morphology are explored in a sample of Croatian individuals. Material and Methods: The sample included 57 TS, 37 KS and 88 control individuals. Dental crown morphology was scored on dental casts according to the Turner-Scott Dental Anthropology System. Results: Incisor shoveling and the hypocone were significantly different between TS individuals and both control and KS individuals. Individuals with TS exhibit lower grades of expression than either group. Furthermore, the number of lingual cusps on the mandibular premolars, the hypoconulid on the mandibular second molar, and cusp 7 on the mandibular first molar were significantly different, though pair-wise comparisons did not elucidate these differences. Tuberculum dentale, distal accessory ridge, and Carabelli's trait were expressed similarly to the control. KS individuals were not significantly different from control individuals for any trait, though this may be related to sample size. Conclusions: Previous studies suggest the loss of an $\mathrm{X}$ chromosome has a reducing effect on dental crown morphology, which is confirmed in this research. TS individuals exhibit generally simpler dental morphology compared to the control sample, though some traits are expressed comparably to the control sample. The effects of KS are less clear. Though previous studies suggest that the presence of an extra $X$ chromosome increases dental crown dimensions, there was no notable effect on crown morphology in this study.
Received: March 28, 2019

Accepted: June 1, 2019

Address for correspondence Associate Professor Jelena Dumančić, $\mathrm{DMD}, \mathrm{PhD}$

University of Zagreb

School of Dental Medicine Department of Dental Anthropology University Hospital Center Zagreb Department of Dental Medicine Gundulićeva 5, 10000 Zagreb, Croatia Phone: +38598615 614

Fax: +38514802159 dumancic@sfzg.hr

Key words

Tooth Crown Morphology; Turner Syndrome; Klinefelter Syndrome; X Chromosome

\section{Introduction}

Turner syndrome (TS) and Klinefelter syndrome (KS) represent the two most common disorders due to aneuploidy of the sex chromosomes. TS occurs in females with complete or partial absence of the second X chromosome, while KS affects males with an extra X chromosome(s). The leading symptom in both syndromes is gonadal dysgenesis. General growth and development are affected with the most consistent feature being short stature in TS and tall stature in KS (e.g. 1, 2). Numerous, but mild, stigmata manifest in the craniofacial region including distinctive cephalometric features (e.g. 3-10).
Uvod

Turnerov sindrom (TS) i Klinefelterov sindrom (KS) dva su najčešća poremećaja uzrokovana aneuploidijom spolnih kromosoma. TS se pojavljuje u žena s potpunim ili djelomičnim nedostatkom jednog kromosoma X, a KS u muškaraca s prekobrojnim kromosomom X. Glavni simptom u oba sindroma je gonadna disgeneza. Zahvaćen je opći rast i razvoj, a najpostojanije obilježje je nizak rast $\mathrm{u}$ TS-u i visok rast $\mathrm{u}$ KS-u (1, 2). Mnogobrojna, ali blaga obilježja, izražena su u kraniofacijalnoj regiji, uključujući specifična kefalometrijska obilježja $(3-10)$.

U osoba s TS-om i KS-om opažen je i izrazit učinak na 
Pronounced effects on dental development have also been noted for TS and KS individuals (11-14). Dental researchers predominantly focus on the effects of these syndromes on tooth crown size, as compared to individuals with a normal chromosomal complement (15-25). Comparatively little research has explored the effects of these aneuploidies on tooth crown morphology (e.g. 21, 26-28). Roots seem to be more affected than the crowns, demonstrating shortening and increased complexity in TS individuals (29-32) and an increase in root length and taurodontism among those with KS (26, $32,33)$. Both syndromes are characterized by a higher incidence of malocclusion $(24,32,34,35)$.

With respect to crown morphology, TS individuals have been characterized by simplification (15, 17, 21, 32, 36-38). Distinctive patterns with respect to control populations are related to an overall reduction in tooth size and/or the thinning of enamel in TS individuals $(15,39)$. Most often these differences manifest as lower grades of expression of traits already present in the population. For example, incisor shoveling is found at lower grades, or is more commonly absent than in control groups (21), the size and number of lingual cusps on mandibular premolars may be reduced (15), the hypocone and/or the hypoconulid of the first molar is typically reduced or absent $(21,27,28)$, and there is a tendency toward absence of Carabelli's trait $(21,28)$. KS individuals show fewer differences in crown morphology, but the presence of additional X chromosomes has been linked to increased expression of Carabelli's trait (32).

Since tooth crown traits are not simply discrete presence/ absence of variables but exhibit a wide range of expression from slight to pronounced, researchers use ranked standards for scoring non-metrical variation of dental traits. The most widely used scheme and recommended standard is the Turner-Scott Dental Anthropology System, formerly ASUDAS $(40,41)$.

Data indicate that sex chromosome aberrations influence dental morphology in a variety of ways. To the knowledge of authors, despite numerous studies, a systematic analysis of morphological variants of all tooth classes in TS and KS individuals has not been published. To get a comprehensive and objective picture of the influence of X-chromosome aberration on the crown morphology of a complete dentition, a sample of Croatian individuals with TS and KS was evaluated using the Turner-Scott Dental Anthropology System.

\section{Material and Methods}

In August 2014, GRS observed nonmetric crown traits on a sample of dental casts of TS and KS individuals and a control group of unrelated individuals at the University of Zagreb School of Dental Medicine ( $\mathrm{n}=182$ ) (Table 1). TS and KS individuals were part of a larger sample of individuals with various sex chromosome anomalies examined in the course of the research project "Characteristics of the Craniofacial Complex in Gonadal Dysgenesis" between 1981 and 1998 (Croatian Ministry of Science and Technology, Project 3-02-383). All individuals underwent dental exams, impressions, and radiographs at the Departments of Dental An- razvoj zuba $(11-14)$. Dentalni istraživači pretežito se usredotočavaju na učinak tih sindroma na veličinu zuba u odnosu prema osobama s normalnim brojem kromosoma (15 $-25)$. Razmjerno se u malo studija istraživao učinak tih aneuploidija na morfologiju krune zuba $(21,26$ - 28). Čini se da su korijeni zahvaćeniji od kruna, a pokazuju skraćenje i veću morfološku kompleksnost u osoba s TS-om (29 - 32) i povećanje duljine i taurodontizam u osoba s KS-om (26, $32,33)$. Oba sindroma obilježava veća incidencija malokluzija $(24,32,34,35)$.

S obzirom na morfologiju zuba, osobe s TS-om obilježava simplifikacija $(15,17,21,32,36-38)$. Obrazac različitosti u odnosu prema kontrolnoj populaciji povezan je s cjelokupnom redukcijom veličine zuba i/ili tanjom caklinom u osoba s TS-om. Najčešće se te razlike manifestiraju kao niži stupnjevi ekspresije svojstava koja su već prisutna u populaciji. Primjerice, lopatasti sjekutići nađeni su u nižim stupnjevima ekspresije ili češće nedostaju negoli u kontrolnim skupinama (21), veličina i broj lingvalnih kvržica na mandibularnim pretkutnjacima mogu biti smanjeni (15), hipokonus i/ili hipokonulid na prvom kutnjaku tipično je smanjen ili nedostaje $(21,27,28)$ i postoji tendencija prema nedostatku Carabellijeva obilježja $(21,28)$. Osobe s KS-om pokazuju manje razlike u morfologiji krune, no prisutnost prekobrojnog Xkromosoma povezuje se s povećanom ekspresijom Carabellijeva obilježja (32).

Kako obilježja kruna zuba nisu jednostavno diskretne varijable prisutno/nedostaje, nego pokazuju širok raspon ekspresije od blagih do izrazitih, istraživači se koriste rangiranim standardima za bodovanje morfoloških varijacija zuba. Najraširenije korištena shema i preporučeni standard jest TurnerScottov dentoantropološki sustav, prije poznat kao ASUDAS $(40,41)$.

Podatci pokazuju da aberacije spolnih kromosoma utječu na morfologiju zuba na različite načine. Koliko je autorima poznato, premda postoje mnogobrojne studije, dosad nije objavljena sustavna analiza morfoloških varijacija svih klasa zuba za osobe s TS-om i KS-om. Da bi se dobila sveobuhvatna i objektivna slika utjecaja aberacija X-kromosoma na morfologiju krune u cijeloj denticiji, uzorak osoba s TS-om i KS-om iz hrvatske populacije procijenjen je uporabom Turner-Scottova dentoantropološkog sustava.

\section{Ispitanici i metode}

U kolovozu 2014. godine G. Richard Scott proučavao je na Stomatološkom fakultetu Sveučilišta u Zagrebu morfološka obilježja krune zuba na uzorku sadrenih modela zuba osoba s TS-om i KS-om te kontrolne skupine osoba koje nisu bile u srodstvu $(\mathrm{n}=182)$ (tablica 1.). Osobe s TS-om i KS-om bile su dio većeg uzorka osoba $s$ različitim anomalijama spolnih kromosoma koje su pregledane u sklopu projekta Osobitosti kraniofacijalnog kompleksa u gonadnoj disgenezi između 1981. i 1998. godine (Ministarstvo znanosti i tehnologije Republike Hrvatske, šifra projekta 3-02-383). Sve su osobe stomatološki pregledane i uzeti su im otisci, te su učinjene rend- 
Table 1 Sample composition

\begin{tabular}{l|c}
\multicolumn{1}{c|}{ Kariotip / Karyotype } & $\mathbf{n}$ \\
Kontrola / Control & $\mathbf{8 8}$ \\
\hline Turnerov sindrom ukupno / Turner Syndrome Total & $\mathbf{5 7}$ \\
\hline $45, \mathrm{X}$ & 33 \\
\hline $45, \mathrm{X} / 46, \mathrm{XX}$ & 6 \\
\hline $45, \mathrm{X} / 46 \mathrm{X}, \mathrm{r}(\mathrm{X})$ & 5 \\
\hline $45, \mathrm{X} / 46, \mathrm{X}, \mathrm{i}(\mathrm{Xq})$ & 5 \\
\hline $45, \mathrm{X} / 46, \mathrm{X}, \mathrm{fr} \mathrm{X}$ & 1 \\
\hline $45, \mathrm{X} / 46, \mathrm{X}, \mathrm{del}(\mathrm{Xp})$ & 1 \\
\hline $46, \mathrm{X}, \mathrm{i}(\mathrm{Xq})$ & 6 \\
\hline Klinefelterov sindrom ukupno / Klinefelter Syndrome Total & $\mathbf{3 7}$ \\
\hline $47, \mathrm{XXY}$ & 35 \\
\hline $47, \mathrm{XXY} / 46, \mathrm{XY}$ & 2 \\
\hline Total & $\mathbf{1 8 2}$ \\
\hline
\end{tabular}

thropology and Orthodontics, School of Dental Medicine, University of Zagreb, Croatia. Karyotypes were determined by chromosome analysis of peripheral lymphocytes and skin fibroblasts. Informed consent was obtained from all participants and legal guardians.

Dental morphological variants were scored following the guidelines of the Turner-Scott Dental Anthropology System, formerly ASUDAS $(40,41)$. The system consists of a set of plaques for permanent teeth, accompanied by trait descriptions and scoring standards. The Croatian population belongs to the Western Eurasian dental complex, which is characterized by relatively simple crown morphology $(42,43)$. As genske snimke u Zavodu za dentalnu antropologiju i Zavodu za ortodonciju Stomatološkog fakulteta Sveučilišta u Zagrebu. Kariotipovi su određeni kromosomskom analizom perifernih limfocita i fibroblasta kože. Svi sudionici i njihovi zakonski skrbnici potpisali su informirani pristanak.

Morfološke varijacije zuba vrjednovane su prema smjernicama Turner-Scottova dentoantropološkog sustava, prije ASUDAS-a $(40,41)$. Sustav se sastoji od seta sadrenih pločica za trajne zube s pratećim tekstualnim opisom i standardom vrjednovanja. Hrvatska populacija spada u zapadno-euroazijski dentalni kompleks koji obilježava razmjerno jednostavna morfologija krune zuba $(42,43)$. $S$ obzirom na to, mnoga

\begin{tabular}{|c|c|c|}
\hline Obilježje / Trait & Zub / Tooth & Prag bodovanja / Breakpoints \\
\hline \multirow[t]{2}{*}{ Lopatasti / Shoveling } & UI1 & $0 / 1 / 2+$ \\
\hline & UI2 & $0 / 1 / 2+$ \\
\hline \multirow[t]{3}{*}{ Tuberculum dentale } & UI1 & $0-1 / 2-3 / 4+$ \\
\hline & UI2 & $0-1 / 2-3 / 4+$ \\
\hline & UC & $0-1 / 2-3 / 4+$ \\
\hline \multirow[t]{2}{*}{ Hipokonus / Hypocone } & UM1 & $<5 / 5$ \\
\hline & UM2 & $0-1 / 2-3 / 4+$ \\
\hline \multirow[t]{2}{*}{ Carabellijevo obilježje / Carabelli’s } & UM1 & $0-1 / 2-4 / 5+$ \\
\hline & UM2 & $0-1 / 2-4 / 5+$ \\
\hline \multirow[t]{2}{*}{ Kvržica 5 / Cusp 5} & UM1 & $0 / 1+$ \\
\hline & UM2 & $0 / 1+$ \\
\hline Distalni akcesorni greben / Distal accessory ridge & LC & $0 / 1+$ \\
\hline \multirow[t]{2}{*}{ Višestruke lingvalne kvržice / Multiple lingual cusps } & LP1 & $0 / 1 / 2+$ \\
\hline & LP2 & $0 / 1 / 2+$ \\
\hline \multirow[t]{2}{*}{ Hipokonulid / Hypoconulid } & LM1 & $0-1 / 2-3 / 4+$ \\
\hline & LM2 & $0 / 1+$ \\
\hline \multirow[t]{2}{*}{ Krržica 6 / Cusp 6} & LM1 & $0 / 1+$ \\
\hline & LM2 & $0 / 1+$ \\
\hline \multirow[t]{2}{*}{ Kvržica 7 / Cusp 7} & LM1 & $0 / 1+$ \\
\hline & LM2 & $0 / 1+$ \\
\hline \multicolumn{3}{|l|}{$\begin{array}{l}\text { U - gornji zub / upper dentition } \\
\mathrm{L} \text { - donji zub / lower dentition } \\
\mathrm{I} \text { - sjekutić / incisor } \\
\mathrm{C} \text { - očnjak / canine } \\
\mathrm{P} \text { - pretkutnjak / premolar } \\
\mathrm{M} \text { - kutnjak / molar }\end{array}$} \\
\hline
\end{tabular}


such, many traits of the Turner-Scott System are rare in European populations, and an insufficient amount of data were collected to present the findings of qualitative research in a coherent and meaningful way.. Additionally, factors like occlusal wear and ante mortem tooth loss precluded observations of some traits. The resulting dataset contains traits regularly observed in the three samples (Table 2).

For these analyses, dental morphological data were recorded following the individual count method (64). The underlying premise of the individual count method is that dental traits are threshold traits; consequently, the higher expression of the trait, regardless of side, is most indicative of the individual's genotype. This method reduces redundancy in the data, and streamlines data collection for subsequent analysis.

Trait frequencies among TS individuals, KS individuals, and the control group were assessed for significant differences using the Pearson's chi-square test. Trait frequencies for which a difference was found among groups were then analyzed using the Fischer's exact test with the Bonferroni correction for multiple comparisons. The Fischer's exact test was used to identify between which specific groups (e.g. TS/ $\mathrm{KS}$, TS/control, KS/control) differences in dental morphology occurred. Sexes were pooled for analyses. Both the TS and KS samples comprise a single sex, and most of the traits examined exhibit negligible sexual dimorphism (42).

\section{Results}

The frequencies for all traits recorded are presented in an appendix to facilitate future comparisons to other populations. Frequencies of the following traits showed no significant differences among groups: tuberculum dentale, Carabelli's trait, cusp 5, canine distal accessory ridge, and cusp 6.

Individuals in the TS sample showed a variety of expression in dental crown traits, including both simple and pronounced grades (Figures 1 and 2). Of the traits examined, only incisor shoveling and the hypocone were significantly different $(\mathrm{p}=0.05)$ between individuals with TS and both control and KS individuals (Tables 3-4). Shoveling among TS individuals is significantly different from the control sample and individuals with KS on both the central and lateral incisors $(p<0.05)$. Inspection of the relative frequencies of each shoveling score indicates that individuals with TS more often exhibit the absence of shoveling than both the control and KS samples, and that when present, it is expressed to a lesser degree (Table 3 ).

The hypocone is significantly different in TS individuals compared to KS and control individuals, on the maxillary first molar, but only from control individuals on the second molar $(\mathrm{p}<0.01)$. As with shoveling, TS individuals are more likely to exhibit the absence of the hypocone than other groups, and instances in which the hypocone is present, it is minimally expressed (Table 4).

Additionally, significant differences were found among groups for lingual cusps on the mandibular premolars, the hypoconulid on the mandibular second molar, and cusp 7 on the mandibular first molar. Although the chi-square test obilježja iz Turner-Scottova dentoantropološkog sustava rijetka su u europskim populacijama te nije prikupljeno dovoljno podataka za smislenu analizu. I čimbenici poput okluzalne abrazije i premortalnog gubitka zuba spriječili su vrjednovanje nekih obilježja. Podatci u rezultatima sadržavaju obilježja koja su bila redovito bodovana za sva tri uzorka (tablica 2.).

Podatci o morfologiji zuba za analizu bilježeni su prema metodi brojanja ispitanika (64). Premisa metode brojanja ispitanika jest da su zubna obilježja osobitosti koje imaju prag; posljedično, što je veća ekspresija obilježja, bez obzira na stranu (lijevu ili desnu), to je bolji pokazatelj genotipa osobe. Ta metoda smanjuje ponavljanje podataka i racionalizira njihovo prikupljanje za kasniju analizu.

Procjena značajnosti razlika u frekvencijama obilježja između osoba s TS-om, KS-om i kontrolne skupine, učinjena je Pearsonovim hi-kvadratnim testom. Frekvencije za koje su nađene razlike između skupina dodatno su analizirane Fischerovim egzaktnim testom s Bonferronijevom korekcijom za višestruke usporedbe. Fischerov egzaktni test korišten je da se odredi između kojih su specifičnih skupina (npr. TS/KS, TS/kontrola, KS/kontrola) pronađene razlike u morfologiji zuba. U kontrolnoj skupini oba su spola bila zajedno. Skupine s TS-om i KS-om su svaka jedan spol, a većina analiziranih obilježja pokazuje zanemariv spolni dimorfizam (42).

\section{Rezultati}

Frekvencije svih obilježja koja su analizirana prikazane su u prilogu da se omoguće buduće usporedbe s drugim populacijama. Frekvencije sljedećih obilježja nisu pokazale značajne razlike između skupina: tuberculum dentale, Carabellijevo obilježje, kvržica 5, distalni akcesorni greben očnjaka i kvržica 6.

Osobe s TS-om pokazale su varijabilnost u ekspresiji morfoloških obilježja kruna zuba, uključujući i jednostavne i naglašene oblike (slike 1. i 2.). Od istraživanih obilježja samo su lopatasti sjekutići i hipokonus bili značajno različiti ( $\mathrm{p}$ $=0,05)$ između osoba s TS-om i drugih dviju skupina - kontrolne i osoba s KS-om (tablice 3. i 4.). Obilježje lopatasti sjekutići bilo je značajno različito kod osoba s TS-om, u odnosu prema kontrolnoj skupini i osobama s KS-om, i na središnjem i na bočnom sjekutiću $(\mathrm{p}<0,05)$. Uvid u relativne frekvencije svakog bodovanja pokazao je da osobe s TS-om pokazuju odsutnost lopatastog oblika češće negoli kontrolna i skupina s KS-om, a kad je obilježje prisutno, ekspresija je nižeg stupnja (tablica 3.).

Hipokonus je bio značajno različit u osoba s TS-om u usporedbi s osobama s KS-om i kontrolnim ispitanicima na prvom maksilarnom kutnjaku, no samo u odnosu prema kontrolnim ispitanicima na drugom kutnjaku $(\mathrm{p}<0,01)$. Kao i u lopatastom obilježju, osobe s TS-om češće negoli druge skupine pokazuju nedostatak hipokonusa, a kad je prisutan, minimalno je izražen (tablica 4.).

Dodatno, značajne razlike među skupinama nađene su za lingvalne kvržice na mandibularnim pretkutnjacima, hipokonulid na drugom mandibularnom kutnjaku i kvržicu 7 na pr- 
Appendix: Frequencies for all traits recorded in control individuals, individuals with Turner syndrome (TS) and individuals with Klinefelter syndrome (KS).

Prilog: Učestalost za sva analizirana obilježja kod kontrolnih osoba, osoba s Turnerovim sindromom (TS) i osoba s Klinefelterovim sindromom (KS)

Lopatasti / Shoveling UI1

\begin{tabular}{c|c|c|c|c|c|c|c|c}
$\mathbf{n}$ & $\mathbf{0}$ & $\mathbf{1}$ & $\mathbf{2}$ & $\mathbf{3}$ & $\mathbf{4}$ & $\mathbf{5}$ & $\mathbf{6}$ & $\mathbf{7}$ \\
\hline 84 & 0.512 & 0.429 & 0.060 & 0.000 & 0.000 & 0.000 & 0.000 & 0.000 \\
\hline 57 & 0.772 & 0.211 & 0.018 & 0.000 & 0.000 & 0.000 & 0.000 & 0.000 \\
\hline 23 & 0.478 & 0.348 & 0.174 & 0.000 & 0.000 & 0.000 & 0.000 & 0.000 \\
$\mathbf{n}$ & $\mathbf{0}$ & $\mathbf{1}$ & $\mathbf{2}$ & $\mathbf{3}$ & $\mathbf{4}$ & $\mathbf{5}$ & $\mathbf{6}$ & $\mathbf{7}$ \\
\hline 86 & 0.535 & 0.372 & 0.093 & 0.000 & 0.000 & 0.000 & 0.000 & 0.000 \\
\hline 52 & 0.846 & 0.154 & 0.000 & 0.000 & 0.000 & 0.000 & 0.000 & 0.000 \\
\hline 22 & 0.409 & 0.500 & 0.091 & 0.000 & 0.000 & 0.000 & 0.000 & 0.000
\end{tabular}

\begin{tabular}{|c|c|c|c|c|c|c|c|c|c|}
\hline Tuberculum dentale UI1 & $\mathbf{n}$ & 0 & 1 & 2 & 3 & 4 & 5 & & \\
\hline Kontrola / Control & 85 & 0.376 & 0.224 & 0.224 & 0.118 & 0.059 & 0.000 & & \\
\hline TS & 56 & 0.357 & 0.339 & 0.143 & 0.089 & 0.071 & 0.000 & & \\
\hline KS & 24 & 0.417 & 0.292 & 0.167 & 0.083 & 0.042 & 0.000 & & \\
\hline Tuberculum dentale UI2 & $\mathbf{n}$ & 0 & 1 & 2 & 3 & 4 & 5 & & \\
\hline Kontrola / Control & 81 & 0.346 & 0.309 & 0.235 & 0.086 & 0.012 & 0.012 & & \\
\hline TS & 50 & 0.200 & 0.320 & 0.220 & 0.200 & 0.040 & 0.020 & & \\
\hline KS & 19 & 0.526 & 0.263 & 0.211 & 0.000 & 0.000 & 0.000 & & \\
\hline Tuberculum dentale UC & $\mathbf{n}$ & 0 & 1 & 2 & 3 & 4 & 5 & & \\
\hline Kontrola / Control & 85 & 0.235 & 0.353 & 0.271 & 0.118 & 0.024 & 0.000 & & \\
\hline TS & 53 & 0.302 & 0.321 & 0.245 & 0.075 & 0.057 & 0.000 & & \\
\hline $\mathrm{KS}$ & 26 & 0.269 & 0.346 & 0.192 & 0.154 & 0.038 & 0.000 & & \\
\hline Hipokonus / Hypocone UM1 & $\mathrm{n}$ & 0 & 1 & 2 & 3 & 4 & 5 & & \\
\hline Kontrola / Control & 87 & 0.000 & 0.000 & 0.000 & 0.023 & 0.540 & 0.437 & & \\
\hline TS & 53 & 0.000 & 0.075 & 0.000 & 0.340 & 0.547 & 0.038 & & \\
\hline KS & 22 & 0.000 & 0.000 & 0.000 & 0.136 & 0.455 & 0.409 & & \\
\hline Hipokonus / Hypocone UM2 & $\mathrm{n}$ & 0 & 1 & 2 & 3 & 4 & 5 & & \\
\hline Kontrola / Control & 78 & 0.077 & 0.218 & 0.077 & 0.372 & 0.244 & 0.013 & & \\
\hline TS & 42 & 0.333 & 0.190 & 0.048 & 0.262 & 0.167 & 0.000 & & \\
\hline KS & 28 & 0.143 & 0.143 & 0.143 & 0.429 & 0.143 & 0.000 & & \\
\hline Carabellijevo obilježje / Carabelli’s UM1 & $\mathbf{n}$ & 0 & 1 & 2 & 3 & 4 & 5 & 6 & 7 \\
\hline Kontrola / Control & 88 & 0.250 & 0.250 & 0.159 & 0.068 & 0.080 & 0.148 & 0.034 & 0.011 \\
\hline TS & 54 & 0.519 & 0.130 & 0.130 & 0.074 & 0.037 & 0.056 & 0.019 & 0.037 \\
\hline KS & 22 & 0.364 & 0.227 & 0.091 & 0.091 & 0.136 & 0.045 & 0.045 & 0.000 \\
\hline Carabellijevo obilježje / Carabelli's UM2 & n & 0 & 1 & 2 & 3 & 4 & 5 & 6 & 7 \\
\hline Kontrola / Control & 74 & 0.838 & 0.083 & 0.012 & 0.012 & 0.012 & 0.024 & 0.000 & 0.000 \\
\hline TS & 38 & 0.868 & 0.053 & 0.000 & 0.000 & 0.026 & 0.026 & 0.000 & 0.026 \\
\hline KS & 27 & 0.889 & 0.037 & 0.000 & 0.037 & 0.037 & 0.000 & 0.000 & 0.000 \\
\hline Kvržica 5 / Cusp 5 UM1 & $\mathbf{n}$ & 0 & 1 & 2 & 3 & 4 & 5 & & \\
\hline Kontrola / Control & 76 & 0.908 & 0.066 & 0.026 & 0.000 & 0.000 & 0.000 & & \\
\hline TS & 49 & 0.857 & 0.122 & 0.000 & 0.000 & 0.020 & 0.000 & & \\
\hline KS & 18 & 0.722 & 0.278 & 0.000 & 0.000 & 0.000 & 0.000 & & \\
\hline Kvržica 5 / Cusp 5 UM2 & $\mathbf{n}$ & 0 & 1 & 2 & 3 & 4 & 5 & & \\
\hline Kontrola / Control & 57 & 0.737 & 0.193 & 0.070 & 0.000 & 0.000 & 0.000 & & \\
\hline TS & 21 & 0.905 & 0.048 & 0.000 & 0.000 & 0.048 & 0.000 & & \\
\hline KS & 19 & 0.842 & 0.053 & 0.053 & 0.053 & 0.000 & 0.000 & & \\
\hline Distalni akcesorni greben / Distal accessory ridge LC & $\mathbf{n}$ & $\mathbf{0}$ & 1 & 2 & 3 & 4 & 5 & & \\
\hline Kontrola / Control & 83 & 0.723 & 0.181 & 0.084 & 0.000 & 0.012 & 0.000 & & \\
\hline TS & 56 & 0.732 & 0.143 & 0.107 & 0.000 & 0.018 & 0.000 & & \\
\hline $\mathrm{KS}$ & 26 & 0.885 & 0.115 & 0.000 & 0.000 & 0.000 & 0.000 & & \\
\hline Broj lingvalnih kvržica / Lingual cusp no. LP1 & n & 0 & 1 & 2 & 3 & 4 & 5 & 6 & 7 \\
\hline Kontrola / Control & 85 & 0.059 & 0.729 & 0.188 & 0.024 & 0.000 & 0.000 & 0.000 & 0.000 \\
\hline TS & 56 & 0.214 & 0.643 & 0.107 & 0.036 & 0.000 & 0.000 & 0.000 & 0.000 \\
\hline KS & 34 & 0.029 & 0.676 & 0.118 & 0.147 & 0.029 & 0.000 & 0.000 & 0.000 \\
\hline
\end{tabular}




\begin{tabular}{|c|c|c|c|c|c|c|c|c|c|}
\hline Broj lingvalnih kvržica / Lingual cusp no. LP2 & $\mathbf{n}$ & 0 & 1 & 2 & 3 & 4 & 5 & 6 & 7 \\
\hline Kontrola / Control & 87 & 0.000 & 0.356 & 0.437 & 0.138 & 0.057 & 0.000 & 0.011 & 0.000 \\
\hline TS & 54 & 0.019 & 0.463 & 0.407 & 0.093 & 0.019 & 0.000 & 0.000 & 0.000 \\
\hline KS & 24 & 0.000 & 0.542 & 0.292 & 0.083 & 0.083 & 0.000 & 0.000 & 0.000 \\
\hline Hipokonulid / Hypoconulid LM1 & $\mathbf{n}$ & 0 & 1 & 2 & 3 & 4 & 5 & & \\
\hline Kontrola / Control & 83 & 0.084 & 0.000 & 0.036 & 0.241 & 0.494 & 0.145 & & \\
\hline TS & 37 & 0.243 & 0.000 & 0.054 & 0.351 & 0.351 & 0.000 & & \\
\hline KS & 7 & 0.143 & 0.143 & 0.000 & 0.143 & 0.571 & 0.000 & & \\
\hline Hipokonulid / Hypoconulid LM2 & $\mathbf{n}$ & 0 & 1 & 2 & 3 & 4 & 5 & & \\
\hline Kontrola / Control & 80 & 0.863 & 0.038 & 0.013 & 0.038 & 0.050 & 0.000 & & \\
\hline TS & 46 & 0.957 & 0.022 & 0.000 & 0.022 & 0.000 & 0.000 & & \\
\hline KS & 19 & 0.789 & 0.105 & 0.053 & 0.000 & 0.053 & 0.000 & & \\
\hline Kvržica 6 / Cusp 6 LM1 & $\mathbf{n}$ & 0 & 1 & 2 & 3 & 4 & 5 & & \\
\hline Kontrola / Control & 78 & 0.885 & 0.038 & 0.077 & 0.000 & 0.000 & 0.000 & & \\
\hline TS & 37 & 0.919 & 0.054 & 0.027 & 0.000 & 0.000 & 0.000 & & \\
\hline KS & 7 & 1.000 & 0.000 & 0.000 & 0.000 & 0.000 & 0.000 & & \\
\hline Kvržica 6 / Cusp 6 LM2 & $\mathbf{n}$ & 0 & 1 & 2 & 3 & 4 & 5 & & \\
\hline Kontrola / Control & 79 & 1.000 & 0.000 & 0.000 & 0.000 & 0.000 & 0.000 & & \\
\hline TS & 45 & 1.000 & 0.000 & 0.000 & 0.000 & 0.000 & 0.000 & & \\
\hline KS & 17 & 0.941 & 0.000 & 0.059 & 0.000 & 0.000 & 0.000 & & \\
\hline Kvržica 7 / Cusp 7 LM1 & $\mathbf{n}$ & 0 & 1 & $1 \mathrm{~A}$ & 2 & 3 & 4 & 5 & \\
\hline Kontrola / Control & 84 & 0.810 & 0.000 & 0.095 & 0.012 & 0.024 & 0.012 & 0.048 & \\
\hline TS & 32 & 0.844 & 0.031 & 0.063 & 0.063 & 0.000 & 0.000 & 0.000 & \\
\hline KS & 7 & 0.857 & 0.000 & 0.000 & 0.143 & 0.000 & 0.000 & 0.000 & \\
\hline Kvržica 7 / Cusp 7 LM2 & $\mathbf{n}$ & 0 & 1 & $1 \mathrm{~A}$ & 2 & 3 & 4 & 5 & \\
\hline Kontrola / Control & 75 & 0.933 & 0.000 & 0.067 & 0.000 & 0.000 & 0.000 & 0.000 & \\
\hline TS & 36 & 0.944 & 0.000 & 0.056 & 0.000 & 0.000 & 0.000 & 0.000 & \\
\hline KS & 16 & 0.938 & 0.000 & 0.063 & 0.000 & 0.000 & 0.000 & 0.000 & \\
\hline
\end{tabular}

$\mathrm{U}$ - gornji zub / upper dentition; L - donji zub / lower dentition; I - sjekutić / incisor; C - očnjak / canine; P - pretkutnjak / premolar; $\mathrm{M}$ - kutnjak / molar

Table 3 Frequency of incisor shoveling. Frequencies among Turner syndrome individuals differ from both the control and Klinefelter syndrome groups $(p=0.05)$

Tablica 3. Učestalost lopatastih sjekutića; učestalost kod osoba s Turnerovim sindromom razlikuje se od one u kontrolnoj skupini i u skupini s Klinefelterovim sindromom $(p=0,05)$

\begin{tabular}{c|c|c|c|c|c|c|c}
\multirow{2}{*}{$\begin{array}{c}\text { Stupanj / } \\
\text { Grade }\end{array}$} & \multicolumn{2}{|c|}{ Kontrola / Control } & \multicolumn{2}{c|}{ Turnerov sindrom / Turner syndrome } & \multicolumn{3}{c}{ Klinefelterov sindrom / Klinefelter } \\
\cline { 2 - 8 } & UI1 & UI2 & UI1 & UI2 & UI1 & UI2 \\
\hline 0 & $0.51(43 / 84)$ & $0.53(46 / 86)$ & $0.77(44 / 57)$ & $0.85(44 / 52)$ & $0.48(11 / 23)$ & $0.41(9 / 22)$ \\
\hline 1 & $0.43(36 / 84)$ & $0.37(32 / 86)$ & $0.21(12 / 57)$ & $0.15(8 / 52)$ & $0.35(8 / 23)$ & $0.50(11 / 22)$ \\
\hline $2+$ & $0.06(5 / 84)$ & $0.09(8 / 86)$ & $0.02(1 / 57)$ & $0.00(0 / 52)$ & $0.17(4 / 23)$ & $0.09(2 / 22)$
\end{tabular}

$\mathrm{U}$ - gornji zub / upper dentition; I - sjekutić / incisor

Table 4 Frequency of the hypocone on maxillary first and second molars. Frequencies on the first molar are significantly different in Turner syndrome individuals than in both the control group and Klinefelter syndrome individuals $(p=0.05)$. On the second molar, Turner syndrome individuals differ only from the control group $(p=0.05)$

Tablica 4. Učestalost hipokonusa na maksilarnim prvim i drugim kutnjacima; učestalost na prvom kutnjaku značajno se razlikuje kod osoba s Turnerovim sindromom u odnosu prema kontrolnoj skupini i osobama s Klinefelterovim sindromom $(p=0,05)$; drugi kutnjak osobe s Turnerovim sindromom razlikuje se samo u odnosu prema kontrolnoj skupini $(p=0,05)$

\begin{tabular}{|c|c|c|c|c|c|c|}
\hline \multirow{2}{*}{ Stupanj / Grade } & \multicolumn{2}{|c|}{ Kontrola / Control } & \multicolumn{2}{|c|}{$\begin{array}{l}\text { Turnerov sindrom / } \\
\text { Turner syndrome }\end{array}$} & \multicolumn{2}{|c|}{$\begin{array}{l}\text { Klinefelterov sindrom / } \\
\text { Klinefelter syndrome }\end{array}$} \\
\hline & UM1 & UM2 & UM1 & UM2 & UM1 & UM2 \\
\hline $\begin{array}{l}<5 \text { (UM1) } \\
0-1 \text { (UM2) }\end{array}$ & $0.56(49 / 87)$ & $0.39(23 / 59)$ & $0.96(47 / 49)$ & $0.52(22 / 42)$ & $0.59(13 / 22)$ & $0.26(8 / 31)$ \\
\hline $\begin{array}{c}5 \text { (UM1) } \\
\text { 2-3 (UM2) }\end{array}$ & $0.44(38 / 87)$ & $0.59(35 / 59)$ & $0.04(2 / 49)$ & $0.31(13 / 42)$ & $0.41(9 / 22)$ & $0.52(16 / 31)$ \\
\hline $4+(\mathrm{UM} 2)$ & NA & $0.02(1 / 59)$ & $\mathrm{NA}$ & $0.17(7 / 42)$ & NA & $0.23(7 / 31)$ \\
\hline
\end{tabular}

$\mathrm{U}$ - gornji zub / upper dentition; M - kutnjak / molar 

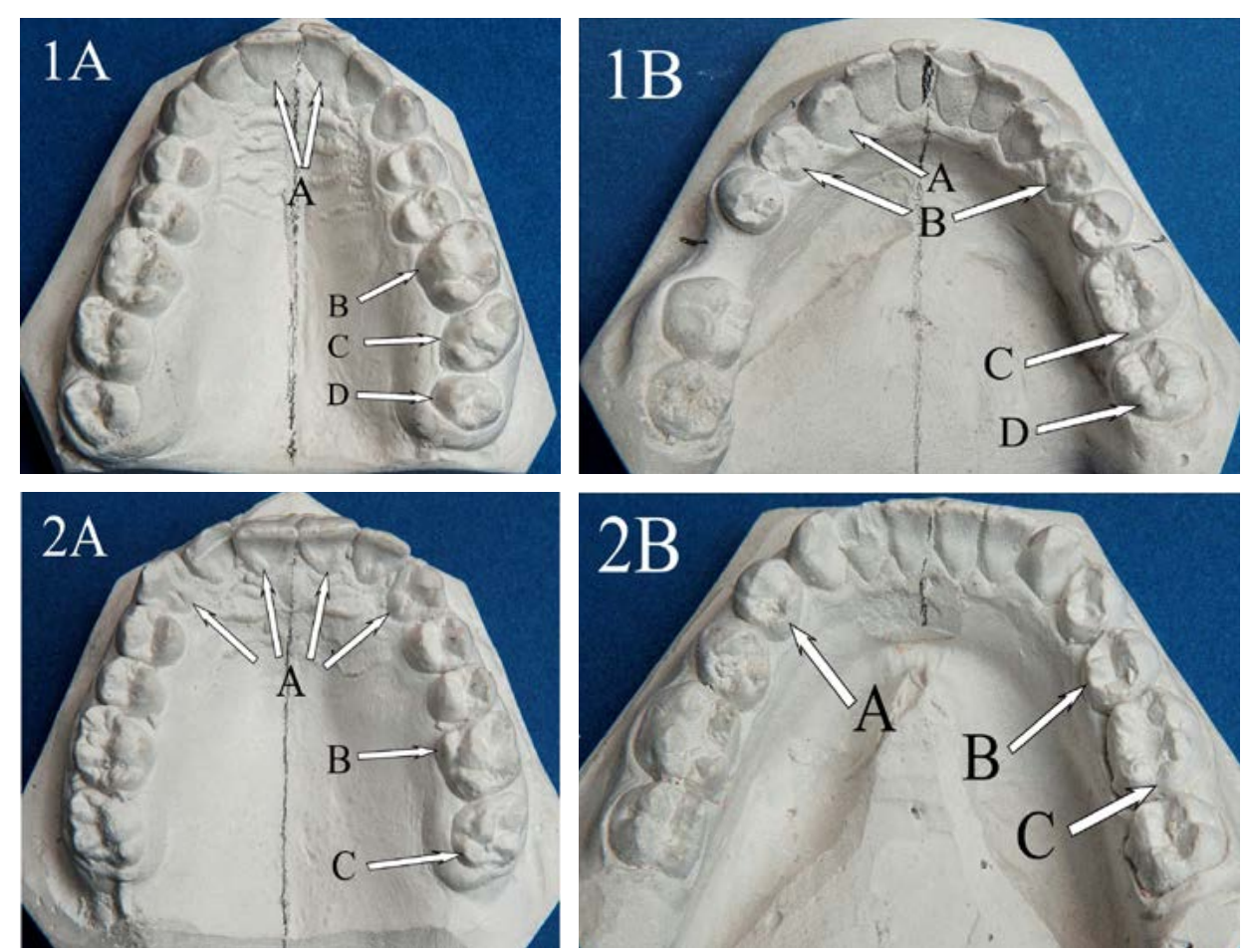

Fig. 1A Turner syndrome, Case 1. TS individuals often show simplified crown morphology. A. Complete absence of shoveling and lingual tubercles on the six upper anterior teeth. B. No expression of Carabelli's trait. C. A compressed upper second molar, also referred to as a 'potato tooth.' D. Upper third molar reduced in size.

Slika 1. A. Turnerov sindrom - slučaj 1; osobe s Turnerovim sindromom često pokazuju simplificiranu morfologiju krune; A) potpuni nedostatak lopatastog obilježja i lingvalnih kvržica na šest gornjih prednjih zuba; B) nema izraženosti Carabellijeva obilježja; C) komprimirani gornji drugi kutnjak, također je poznat pod nazivom krumpirasti zub; D) gornji treći kutnjak reducirane veličine

Fig. 1B Turner syndrome, Case 1. Morphological simplification in lower dentition. A. Lower canine with no marginal or accessory ridges. B. Lower first premolars have greatly reduced lingual cusps with no free apex. C. Significantly reduced hypoconulid on lower first molar. D. Pronounced reduction of entoconid (distolingual cusp) on lower second molar.

Slika 1. B. Turnerov sindrom - slučaj 1; morfološka simplifikacija u donjoj denticiii; A) donji očnjak bez marginalnih ili akcesornih grebena; B) donji prvi pretkutnjaci imaju značajno reducirane lingvalne kvržice bez slobodnog vrška; C) značajno reduciran hipokonulid na donjem prvom kutnjaku; D) izrazita redukcija entokonida (distolingvalne kvržice) na donjem drugom kutnjaku

Fig. 2A Turner syndrome, Case 2. Not all TS individuals show simplification of crown morphology. A. Moderate to pronounced lingual tubercles on all six upper anterior teeth. B. A large grade 7 Carabelli's trait on upper first molar (second molar also has a distinctive Carabelli's trait). C. The upper second molar has a pronounced hypocone (distolingual cusp).

Slika 2. A. Turnerov sindrom - slučaj 2; ne pokazuju sve osobe s Turnerovim sindromom simplifikaciju morfologije krune; A) umjerene do izrazite lingvalne kvržice na svih šest gornjih prednjih zuba; B) veliko Carabellijevo obilježje 7. stupnja na gornjem prvom kutnjaku (drugi kutnjak također ima prepoznatljivo Carabellijevo obilježje); C) gornji drugi kutnjak s izrazitim hipokonusom (distolingvalna kvržica)

Fig. 2B Turner syndrome, Case 2. In the lower dentition of the same individual, some morphology is evident although crown simplification is a hallmark of the Western Eurasian dentition. A. Two distinct lingual cusps with free apices on the lower first premolar. B. Distinct lingual cusp on lower second premolar. C. Distinct hypoconulid on lower first molar.

Slika 2. B. Turnerov sindrom - slučaj 2; u donjoj denticiji iste osobe vidljivo je poneko morfološko obilježje, premda je simplifikacija krune pečat zapadno-euroazijske denticije; A) dvije izrazite lingvalne kvržice sa slobodnim vršcima na donjem prvom pretkutnjaku; B) izrazita lingvalna kvržica na donjem drugom pretkutnjaku; C) izrazit hipokonulid na donjem prvom kutnjaku

identified that significant differences exist, the Bonferroni correction applied to the Fisher's test did not identify any significant pair-wise comparisons. This difference is likely due to the conservative nature of the Bonferroni correction, which is designed to combat Type I error, or false positives, at the cost of a reduction in statistical power, or an increase in false negatives.

The frequencies of lingual premolar cusps and the hypoconulid on the second molar follow similar patterns to shoveling and the hypocone; that is, individuals with TS more frequently exhibit trait absence than either the control or KS samples (Appendix). TS individuals, for example, fail to exhibit a lingual cusp on the lower first premolar $21.4 \%$ of the time (Figure 1B). This simplified phenotype is far less com- vom mandibularnom kutnjaku. Premda je hi-kvadratni test pokazao da postoje značajne razlike, Bonferronijeva korekcija primijenjena na Fischerov test nije identificirala značajne usporedbe parova. Ta razlika vjerojatno se može pripisati konzervativnoj prirodi Bonferronijeve korekcije koja je osmišljena da se suzbije pogreška tipa I., tj. lažno pozitivna, po cijenu redukcije statističke moći, tj. povećanja lažno negativnih.

Frekvencije lingvalnih kvržica pretkutnjaka i hipokonulida na drugom kutnjaku pokazuju sličan obrazac poput obilježja lopatasti i hipokonus: osobe s TS-om češće pokazuju odsutnost obilježja negoli kontrolni uzorak i uzorak s KS-om (prilog). Primjerice, osobe s TS-om nemaju lingvalnu kvržicu na donjem prvom pretkutnjaku u $21,4 \%$ slučajeva (slika 1. b). Taj pojednostavnjeni fenotip mnogo je rjeđi kod kon- 
mon in control (5.9\%) and KS (2.9\%) individuals. In cases where TS individuals express multiple lingual cusps or the hypoconulid, it is typically of a lesser degree than in the other groups. The frequency distribution for cusp 7 is different. TS individuals do not seem to have a marked increase in absence of the trait compared to other groups. However, the control sample is the only one of the three groups to have non-zero frequencies for expression above grade 2 , which may contribute to this difference.

Individuals with $\mathrm{KS}$ were not significantly different from the control individuals for any trait, though this may be a product of the small number of individuals observed with KS.

\section{Discussion}

The present research investigated nonmetric crown traits in TS and KS individuals, who express clinical manifestations of X chromosome aneuploidy. One benefit of this research is the systematic analysis of complete dentitions using a standard established for that purpose, thus giving an insight on the influence of the X chromosome on tooth crown morphology of a variety of tooth classes. Secondly, an assessment of nonmetric crown traits can be difficult and training is required to confidently distinguish between grades of individual traits. Since evaluation was performed by an experienced researcher (GRS), who is one of the authors of the standard, these distinctions were made with confidence, which is another benefit to this study. The TS and KS samples were representative, both in the presence of common karyotypes and in their relative distributions (Table 1).

Ten traits in total were present both in syndromic groups and in the control group (Table 2). TS individuals showed a great variety including both simple and pronounced grades of expression. While some traits (shoveling, hypocone, lingual premolar cusps, hypoconulid on the second molar and cusp 7 on the first molar) were reduced in the TS group, the others showed frequencies and expressions comparable to those in the control sample (tuberculum dentale, canine distal accessory ridge, Carabelli's trait, cusp 5, and cusp 6). This finding is new, as in the literature tooth crown morphology in TS is described as simplified $(15,17,21,28,32,36-39)$.

As KS manifest the opposite findings to TS regarding body stature, craniofacial patterning, mandibular growth, and tooth size, one would expect the same for tooth crown morphology. However, this study did not reveal any significant differences between KS and the control group. This result may be influenced by the small number of individuals in KS group, which is a potential limitation of this study.

Aneuploidies of the X chromosome, including KS and TS, affect tooth crown size (15-25). TS and KS influence tooth size due to differences in the number of $\mathrm{X}$ chromosomes, and consequently differences in amelogenin secretion and enamel formation $(24,32)$. The $\mathrm{X}$ chromosome has been linked to enamel thickness as well as the rate of dental development $(2,16,32,39,44-46)$. Consequently, males affected by KS have larger teeth than males with a normal chromosomal complement $(19,32,36,44,47-49)$. The importance trolnih ispitanika (5,9 \%) i osoba s KS-om (2,9\%). U slučaju kada osobe TS-om imaju višestruke lingvalne kvržice ili hipokonulid, to je tipično nižeg stupnja negoli u drugim skupinama.

Distribucija frekvencija za kvržicu 7 je drukčija. Čini se da u osoba s TS-om nije izrazito povećana odsutnost obilježja u odnosu prema drugim skupinama. Međutim, od svih triju skupina samo je u kontrolnom uzorku pronađena ekspresija obilježja veća od stupnja 2, što možda pridonosi razlici.

Osobe $s$ KS-om nisu se značajno razlikovale od osoba iz kontrolne skupine ni za jedno obilježje, premda to je možda posljedica malog broja osoba s KS-om koji je istraživan.

\section{Rasprava}

U ovoj studiji istraživana su nemetrička obilježja zubnih kruna u osoba s TS-om i KS-om koje izražavaju kliničke manifestacije aneuploidije kromosoma X. Jedna od prednosti ove studije jest sustavna analiza cjelokupne denticije uporabom standarda koji je ustanovljen za tu namjenu, a daje nam uvid u utjecaj X-kromosoma na morfologiju krune u raznim klasama zuba. Drugo, određivanje nemetričkih obilježja krune može biti zahtjevno i potrebna je vježba da bi se pouzdano razlikovali stupnjevi pojedinog obilježja. Kako je procjenu radio iskusan istraživač (GRS) koji je i jedan od autora standarda, razlikovanja su pouzdana, što je druga prednost ove studije. Uzorci osoba s TS-om i KS-om dobro su reprezentirali sindrome s najčešćim kariotipovima i njihovim relativnim distribucijama (tablica 1.).

U skupinama sa sindromima i u kontrolnoj skupini ukupno je bilo deset obilježja (tablica 2.). Osobe s TS-om pokazale su veliku varijabilnost, uključujući i jednostavne oblike i naglašene stupnjeve ekspresije. Dok su neka obilježja (lopatasti hipokonus, lingvalne kvržice pretkutnjaka, hipokonulid na drugom kutnjaku i kvržica 7 na prvom kutnjaku) bila reducirana u skupini s TS-om, druga su pokazala frekvenciju i ekspresiju sličnu onima u kontrolnoj skupini (tuberculum dentale, distalni akcesorni greben očnjaka, Carabellijevo obilježje, kvržica 5 i kvržica 6). To je novi nalaz s obzirom na to da se dosad u literaturi morfologija krune u TS-u opisivala kao pojednostavnjena $(15,17,21,28,32,36$ - 39).

Budući da KS pokazuje nalaze suprotne onima u TS-u kad je riječ o tjelesnoj visini, kraniofacijalnoj morfologiji, rastu mandibule i veličini zuba, isto bi se moglo očekivati i u morfologiji zubnih kruna. Ipak, ovo istraživanje nije otkrilo značajne razlike između KS-a i kontrolne skupine. Na taj rezultat možda je utjecao mali broj osoba u skupini s KS-om, što je potencijalni nedostatak ovog istraživanja.

Aneuploidije kromosoma X, uključujući TS i KS, utječu na veličinu krune zuba $(15-25)$. TS i KS utječu na veličinu zuba zbog razlike u broju kromosoma $\mathrm{X}$ i posljedično razlike $\mathrm{u}$ sekreciji amelogenina te u formiranju cakline $(24,32)$. Kromosom $\mathrm{X}$ povezuje se $s$ debljinom cakline te brzinom razvoja zuba $(2,16,32,39,44$ - 46). Zbog toga muškarci s KS-om imaju veće zube od muškaraca s normalnim kromosomskim komplementom (19, 32, 36, 44, 47 - 49). Važnost kromosoma X za veličinu zuba izravno je povezana s brojem preko- 
of the $\mathrm{X}$ chromosome to tooth size is directly related to the number of extra $\mathrm{X}$ chromosomes, and its effect on general growth patterns and enamel thickness (50). Similarly, females affected by monosomatic $(45, \mathrm{X})$, structural aberrations, and mosaic forms of TS have smaller teeth due to the absence of all or part of an X chromosome (13, 15, 17, 20, 23, 36, 37, $51,52)$. Interestingly, because TS is an aneuploidy specifically of the X chromosome, it is only enamel formation that is affected; dentine does not appear to be affected by TS (17). Odontometric investigations on the effect of chromosomal aneuploidies on the dentition have identified an inverse relationship between the degree of size reduction and the length of time a given tooth requires for development. Teeth that take longer to develop, such as the canines, have less reduced crown diameters, whereas quickly developing teeth, like the molars, are more reduced $(23,36)$.

The discussion of the effect on tooth size is an important consideration with respect to dental crown morphology. There is a positive association between crown size and crown complexity, meaning that larger teeth exhibit crown traits more frequently and to a more pronounced degree (5366). The size and degree of expression of Carabelli's trait is reduced with small tooth size $(21,26,28)$. Additionally, minimal expression of Carabelli's trait and hypocone reduction have also been linked to one another $(57,65,67,68)$. Although crown size and complexity are correlated, there is not necessarily a causal link.

The most likely explanation for the relationship between tooth size and crown complexity is that both size and cusp number and pattern are regulated by the same or related processes (59). The role of enamel knots in tooth development may be critical. Enamel knots are regions of non-dividing cells on the inner enamel epithelium present during tooth formation. Signaling factors released by these regions promote cell growth in adjacent regions that ultimately form the cusps of the tooth (69-72). Additionally, several studies suggest that substances released by the enamel knots are involved in the regulation of crown size and cusp pattern (73-77). Nakayama and colleagues (28) argue that the complement of $\mathrm{X}$ chromosomes affects the development of enamel knots. If Nakayama and colleagues are correct in their hypothesized relationship between the $\mathrm{X}$ chromosome and the formation of enamel knots, then individuals missing an X chromosome, or part of one, would be expected to exhibit smaller teeth with fewer cusps, which is supported both by odontometric data $(13,15,17,20,23,36,37,51,52)$ and the frequencies of morphological traits observed in this sample as well as in previous work $(21,26-28)$.

In this sample, individuals with TS exhibit significantly different frequencies for incisor shoveling and the hypocone, compared to control individuals and individuals with KS. Similar patterns were observed in Finnish and Norwegian samples $(21,26,28,68)$. Individuals with TS exhibit multiple lingual premolar cusps less frequently than the control group and the KS group. Although rarely examined, previous work has found that TS can result in fewer lingual cusps on the mandibular premolars (15). Furthermore, work on Carabelli's trait and hypocone reduction $(21,26,28,68)$ brojnih X-kromosoma i njihovim učinkom na opće obrasce rasta i debljinu cakline (50). Slično, žene koje su pogođene monosomijom kromosoma X $(45, \mathrm{X})$, strukturnim aberacijama i mozaičnim oblicima kariotipa TS-a, imaju manje zube zbog nedostatka dijela ili cijelog X-kromosoma $(13,15,17$, $20,23,36,37,51,52)$. Budući da je TS aneuploidija specifičnost kromosoma X, zanimljivo je da utječe samo na stvaranje cakline, a čini se da dentin nije pod utjecajem TS-a (17). Odontometrijska istraživanja utjecaja kromosomskih aneuploidija na denticiju otkrila su obrnuti odnos između stupnja redukcije veličine i duljine vremena koje je određenom zubu potrebno za razvoj. Zubima koji se razvijaju dulje, poput očnjaka, manje je reduciran promjer krune, a zubi koji se razvijaju brzo, poput kutnjaka, jače su reducirani $(23,36)$.

Rasprava o učinku na veličinu zuba važna je i za morfologiju krune zuba. Postoji pozitivna veza između veličine krune zuba i kompleksnosti krune, što znači da veći zubi češće pokazuju morfološka obilježja i u većem stupnju izraženosti $(53$ - 66). Veličina i stupanj ekspresije Carabellijeva svojstva reducirani su sa smanjenom veličinom zuba $(21,26,28)$. Uz to, minimalna ekspresija Carabellijeva obilježja i redukcija hipokonusa također su uzajamno povezani $(57,65,67,68)$. Premda su veličina i kompleksnost krune povezani, to nije nužno uzročno-posljedična veza.

Najvjerojatnije objašnjenje za povezanost veličine zuba i kompleksnosti krune jest da su i veličina zuba te broj i uzorak kvržica regulirani istim ili povezanim procesima (59). Ključnu uloga u razvoju zuba mogli bi imati caklinski čvorovi. Caklinski čvorovi su regije unutarnjeg caklinskog epitela, prisutnog tijekom razvoja zuba, u kojem se nalaze stanice koje se ne dijele. Iz tih regija otpuštaju se signalni čimbenici koji potiču rast stanica u susjednim regijama koje u konačnici formiraju zubne kvržice (69-72). U nekoliko studija također se sugerira da su tvari koje otpuštaju caklinski čvorovi uključene u regulaciju veličine krune i uzorka kvržica $(73-77)$. Nakayama i suradnici (28) tvrde da komplement kromosoma X utječe na razvoj caklinskih čvorova. Ako je točna njihova hipoteza o povezanosti kromosoma X sa stvaranjem caklinskih čvorova, tada bi se kod osoba s nedostatkom kromosoma X ili njegova dijela očekivali manji zubi s manje kvržica, što su potvrdili i odontometrijski podatci $(13,15,17,20,23,36,37,51$, 52) i frekvencije morfoloških obilježja koje su nađene u ovom uzorku i u ranijim radovima $(21,26-28)$.

U ovom uzorku osobe s TS-om pokazuju značajno različitu učestalost lopatastih sjekutića i hipokonusa u odnosu prema kontrolnim ispitanicima i osobama s KS-om. Sličan obrazac uočen je i u finskom i norveškom uzorku $(21,26,28,68)$. Osobe s TS-om rjeđe imaju multiple lingvalne kvržice pretkutnjaka, negoli kontrolna skupina i skupina s KS-om. Premda su rijetko istraživane, u ranije objavljenom radu ističe se da TS može rezultirati s manje lingvalnih kvržica na mandibularnim pretkutnjacima (15). Nadalje, radovi o Carabellijevu obilježju i redukciji hipokonusa $(21,26,28,68)$ povezali su TS s općom redukcijom broja kvržica, u nekim slučajevima neovisno o redukciji veličine krune. Generalizirana povezanost između TSa i redukcije kvržica može objasniti potencijalne razlike koje su nađene u ekspresiji hipokonulida i kvržice 7, premda, prema našim spoznajama, takvi obrasci dosad nisu opisani. 
has linked TS to a general reduction in cusp number, in some cases independent of the reduction in crown size. The generalized relationship between TS and cusp reduction may also explain the potential differences seen in expression of the hypoconulid and cusp 7, though to our knowledge, these patterns have not been previously described.

Several studies on the influence of different TS karyotypes on tooth size and morphology demonstrated that the isochromosome karyotype 46,X,i(Xq) (lack of the short arm $\mathrm{Xp}$ with duplication of the long arms $\mathrm{Xq}$ ) is the most divergent showing the most reduced crown dimensions, the mosaic 45,X/46,XX karyotype (having both normal XX and one X sex chromosome cell lines) exhibits the largest crown dimensions, close to those of normal females, and the 45, X karyotype is intermediate to these extremes $(13,17,25,37,68)$. In a recent study by Nakayama et al., the difference between karyotypes in frequencies of Carabelli's cusp was not significant (68). Surprisingly, the same study found the absence of the hypocone to be most frequent in 45, X/46, XX individuals and the least frequent in the 45, X karyotype (68). Smaller crown size was associated with a reduced distolingual cusp but not with a reduction in Carabelli's cusp. The hypothesized explanation of these findings is that the candidate genes (promoters) for controlling tooth crown size are located in the region PAR1 in Xp, whereas their inhibitor is located in the region PAR2 of Xq. Therefore, phenotypic variation is a result of an interactive equilibrium between the promoters and inhibitors genes. The process of unilateral $\mathrm{X}$ chromosome inactivation should also be considered. The comparison of TS karyotypes was not the aim of the present investigation; however, it is interesting that the two TS cases showing the largest grades of Carabelli's trait on M1 and a distinctive Carabelli's trait on M2 (Figures 2A and 2B) were both of 45, X karyotype. Where crown morphology is concerned, it is possible that 45 , X karyotype is phenotypically closest to normal females.

If the size of the crown is correlated with morphological complexity, e.g. (53-55, 57, 58, 60, 63-66), it might be expected that individuals with KS would exhibit more complex dental morphology. Although the presence of an additional X chromosome does correlate with an increase in crown size in KS males $(32,36,44,47-49)$, it does not appear to have any effect on crown morphology in the Croatian sample. Mayhall and Alvesalo (78) also did not find differences between KS and normal males in Carabelli's trait expression. In the light of the hypothesis by Nakayama et al. (68), it is possible that two copies of the X chromosome in KS individuals contribute to a dosage of promoter and inhibitor genes that result in the suppression of the development of complex dental morphology.

The data on this Croatian sample are consistent with other studies on the effects of chromosomal aneuploidies on dental morphology, supporting the role of the X chromosome both in the production of enamel, and the development and pattern of tooth cusps. Though most traits exhibit the simplification expected in TS individuals, it is important to note that for some traits (tuberculum dentale, canine distal accessory ridge, Carabelli's trait, cusp 5, and cusp 6), TS indi-
U nekoliko studija istraživao se utjecaj različitih kariotipova TS-a na veličinu i morfologiju zuba te se pokazalo da je kariotip s izokromosomom 46,X,i (Xq) (manjak kratkog kraka Xp-a uz udvostručenje dugog kraka Xq) najrazličitiji i pokazuje najveću redukciju dimenzija krune, mozaični kariotip 45,X/46,XX (dvije stanične linije - jedna s jednim kromosomom X i jedna s normalnim kariotipom XX) ima najveće dimenzije kruna slične onima u normalnih žena, te kariotip 45,X koji je između ovih ekstrema $(13,17,25,37,68)$. $\mathrm{U}$ nedavnom istraživanju Nakayame i suradnika nije nađena značajna razlika između kariotipova u učestalosti Carabellijeve kvržice (68). Iznenađuje da je u istom istraživanju nađeno da je nedostatak hipokonusa najčešći u osoba $s$ kariotipom 45,X/46,XX, a najrjeđi u kariotipu 45,X. Manja dimenzija krune bila je povezana s redukcijom distolingvalne kvržice, ali ne s redukcijom Carabellijeve kvržice. Pretpostavka koja objašnjava te nalaze jest da su određeni geni (promotori), koji kontroliraju veličinu krune, locirani u regiji PAR1 na Xp kra$\mathrm{ku}$, a njihov inhibitor lociran je u regiji PAR2 na Xq kraku. Zbog toga su fenotipske varijacije rezultat interaktivne ravnoteže između gena promotora i inhibitora. U obzir treba uzeti i jednostranu inaktivaciju kromosoma X. Svrha ovoga rada nije bila usporedba kariotipova TS-a, no zanimljivo je da su dva slučaja s TS-om koja su pokazivala najveći stupanj ekspresije Carabellijeva obilježja na prvom kutnjaku i prepoznatljivo Carabellijevo obilježje na drugom kutnjaku (slike 2. A i 2. B), bila kariotip 45,X. Kad je riječ o morfologiji krune, moguće je da je kariotip 45,X fenotipski najbliži normalnim ženama.

Ako je veličina krune zuba povezana $s$ morfološkom kompleksnosti (npr. 53 - 55, 57, 58, 60, 63 - 66), može se očekivati da će osobe s KS-om pokazivati kompleksniju morfologiju zuba. Premda je prisutnost dodatnog kromosoma X povezana s povećanjem dimenzija krune u muškaraca s KSom (32, 36, 44, 47 - 49), čini se da nema učinka na morfologiju krune u hrvatskom uzorku. Mayhall i Alvesalo (78) također nisu našli razlike u ekspresiji Carabellijeva obilježja između muškaraca s KS-om i normalnih muškaraca. U svjetlu hipoteze Nakayame i suradnika (68), moguće je da dva primjerka kromosoma X kod osoba s KS-om pridonose dozi gena promotora i inhibitora koja rezultira supresijom razvoja kompleksne morfologije zuba.

Podatci iz ovoga hrvatskog uzorka slažu se s drugim istraživanjima o učinku kromosomskih aneuploidija na morfologiju zuba i potvrđuju ulogu kromosoma $\mathrm{X}$ u produkciji cakline i u razvoju i obrascu zubnih kvržica. Premda većina obilježja pokazuje očekivanu simplifikaciju u osoba s TS-om, bitno je istaknuti da neka obilježja (tuberculum dentale, distalni akcesorni greben očnjaka, Carabellijevo obilježje, kvržica 5 i kvržica 6) kod njih pokazuju učestalost i ekspresiju sličnu onima u kontrolnom uzorku. Kad se uzmu u obzir nalazi iz ovog istraživanja, svrstavanje učinka TS-a na morfologiju krune zuba u simplifikaciju previše je pojednostavnjena kategorizacija. Postojeća literatura usredotočena je na ispitanike iz europskih uzoraka. Zapadno-euroazijski dentalni kompleks već obilježava simplificirana morfologija krune zuba (42, 43, 79), stoga utjecaj ovih aneuploidija u populacijama s kompleksnijom morfologijom ostaje nepoznat. 
viduals have frequencies and expressions comparable to those seen in the control sample. Considering the findings of this research, classifying the effect of TS on dental crown morphology as 'simplification' may be an overly simplistic categorization. The available literature focuses on individuals from European samples. The Western Eurasian dental complex is already characterized by simplified crown morphology ( 42 , $43,79)$; therefore, the effects of these aneuploidies on populations with more complex morphology remain unknown.

\section{Conclusions}

Aneuploidies of the X chromosome affect dental development. The effect on tooth size is well-documented, but comparatively little research has focused on its effects on dental crown morphology. Previous studies suggest that the loss of $\mathrm{X}$ chromosome material has a reducing effect on dental crown morphology, which has been largely confirmed in this research. Although a typical Western Eurasian dentition is characterized by simplification, individuals with TS generally exhibit simpler morphology, particularly in expressions of incisor shoveling and the reduction of the hypocone. However, not all crown traits seem to be equally affected by the absent $\mathrm{X}$ chromosome; tuberculum dentale, canine distal accessory ridge, and Carabelli's trait are in particular expressed similarly to the control sample. The effects of KS are less clear and may be elucidated through the study of populations with a more complex dental morphology. Though the presence of an extra $\mathrm{X}$ chromosome increases dental crown dimensions, there was no notable effect on crown morphology in this study.

\section{Acknowledgements}

The research project "Characteristics of the Craniofacial Complex in Gonadal Dysgenesis" was supported by the Croatian Ministry of Science and Technology, grant 3-02-383.

\section{Conflict of interest}

The authors have declared that no competing interests exist.

\section{Zaključak}

Aneuploidije kromosoma X utječu na razvoj zuba. Utjecaj na veličinu zuba dobro je dokumentiran, a razmjerno manje istraživanja usmjereno je na učinke na morfologiju krune zuba. $U$ dosadašnjim istraživanjima sugerira se da gubitak materijala kromosoma X reducirajuće djeluje na morfologiju krune zuba, što je većim dijelom potvrđeno u ovom istraživanju. Premda tipičnu zapadno-euroazijsku denticiju karakterizira simplifikacija, osobe s TS-om pokazuju općenito još jednostavniju morfologiju, osobito u ekspresiji lopatastih sjekutića i redukciji hipokonusa. Međutim, čini se da nisu sva obilježja krune zuba podjednako pogođena nedostatkom kromosoma X - neka obilježja slično su izražena kao u kontrolnom uzorku, osobito tuberculum dentale, distalni akcesorni greben očnjaka i Carabellijevo obilježje. Učinci KS-a manje su jasni i mogli bi se rasvijetliti istraživanjima u populacijama $s$ kompleksnijom morfologijom zuba. Premda dodatni kromosom X povećava dimenzije krune zuba, u ovom istraživanju nije bilo značajnog učinka na morfologiju krune zuba.

\section{Zahvale}

Znanstveno-istraživački projekt Osobitosti kraniofacijalnog kompleksa u gonadnoj disgenezi financiralo je Ministarstvo znanosti i tehnologije Republike Hrvatske, šifra: 3-02-383.

\section{Sukob interesa}

Autori nisu bili u sukobu interesa.

\section{Sažetak}

Svrha: Turnerov sindrom (TS) i Klinefelterov sindrom (KS) dvije su najčešće aneuploidije kromosoma $\mathrm{X}$ i svaka je povezana sa sustavnim poremećajima u rastu i razvoju. Istraživan je utjecaj tih sindroma na morfologiju krune zuba na uzorku osoba iz Hrvatske. Ispitanici i postupci: Uzorak je sadržavao 57 osoba s TS-om, 37 s KS-om i 88 u kontrolnom uzorku. Morfologija kruna zuba vrjednovana je prema Turner-Scottovu dentoantropološkom sustavu. Rezultati: Lopatasti sjekutići i hipokonus bili su značajno drukčiji u osoba s TS-om u odnosu prema kontroli i osobama s KS-om. Osobe s TS-om pokazuju niže stupnjeve ekspresije negoli one u drugim skupinama. Nadalje, značajno je različit bio broj lingvalnih kvržica na mandibularnim pretkutnjacima, hipokonulid na mandibularnom drugom kutnjaku i kvržica 7 na mandibularnom prvom kutnjaku, premda uparena usporedba nije rasvijetlila te razlike. Tuberculum dentale, distalni akcesorni greben očnjaka i Carabellijevo obilježje , bili su izraženi slično kao u kontroli. Osobe s KS-om nisu se značajno razlikovale od kontrolnog uzorka ni u jednom obilježju, što je možda povezano s veličinom uzorka. Zaključak: U dosadašnjim istraživanjima autori pretpostavljaju da gubitak kromosoma $\mathrm{X}$ reducirajuće utječe na morfologiju krune zuba, što je potvrđeno u ovom istraživanju. Osobe s TS-om pokazuju opće pojednostavljenu morfologiju zuba u usporedbi s kontrolnim uzorkom, premda su neka obilježja izražena podjednako kao u kontrolnom uzorku. Učinci KS-a manje su jasni. Premda se u dosadašnjim istraživanjima sugerira da prekobrojni kromosom $X$ povećava dimenzije zubne krune, $u$ ovom istraživanju nije nađen značajan učinak na morfologiju krune zuba.
Zaprimljen: 28. ožujka 2019. Prihvaćen: 1. lipnja 2019.

Adresa za dopisivanje izv. prof. dr. sc. Jelena Dumančić Sveučilište u Zagrebu, Stomatološki fakultet

Zavod za dentalnu antropologiju Klinika za stomatologiju KBC-a Zagreb Klinički zavod za obiteljsku stomatologiju

Gundulićeva 5, 10000 Zagreb, Hrvatska

tel: +38598615614

dumancic@sfzg.hr

Ključne riječi

morfologija krune zuba, Turnerov sindrom, Klinefelterov sindrom, kromosom $X$ 


\section{References}

1. Tanner JM, Prader A, Habich H, Ferguson-Smith MA. Genes on the $Y$ chromosome influencing rate of maturation in man: Skeletal age studies in children with Klinefelter's (XXY) and Turner's (XO) syndromes. Lancet. 1959 Aug 22;2(7095):141-4.

2. Garn SM, Rohmann CG. X-linked inheritance of developmental timing in man. Nature. 1962 Nov 17;196:695-6.

3. Jensen BL. Craniofacial morphology in Turner syndrome. J Craniofac Genet Dev Biol. 1985;5(4):327-40.

4. Babić M, Sćepan I, Mićić M. Comparative cephalometric analysis in patients with X-chromosome aneuploidy. Arch Oral Biol. 1993 Feb;38(2):179-83.

5. Brown T, Alvesalo L, Townsend GC. Craniofacial patterning in Klinefelter (47 XXY) adults. Eur J Orthod. 1993 Jun;15(3):185-94.

6. Brkic H, Kaic Z, Poje Z, Singer Z. Shape of the craniofacial complex in patients with Klinefelter syndrome. Angle Orthod. 1994;64(5):371-6.

7. Midtbø M, Wisth PJ, Halse A. Craniofacial morphology in young patients with Turner syndrome. Eur J Orthod. 1996;18(3):215-25.

8. Peltomäki T, Alvesalo L, Isotupa K. Shape of the craniofacial complex in 45,X females: cephalometric study. J Craniofac Genet Dev Biol. 1989;9(4):331-8.

9. Dumancic J, Kaic Z, Varga ML, Lauc T, Dumic M, Milosevic SA, et al. Characteristics of the craniofacial complex in Turner syndrome. Arch Oral Biol. 2010 Jan;55(1):81-8.

10. Juloski J, Dumančić J, Šćepan I, Lauc T, Milašin J, Kaić Z, et al. Growth hormone positive effects on craniofacial complex in Turner syndrome. Arch Oral Biol. 2016;71:10-5.

11. Kollar EJ. Epithelial-mesenchymal interaction in the mammalian in tegument: tooth development as a model for instructive induction. In: Sawyer RH, Fallon J, editors. Epithelial-mesenchymal interaction in development. New York: Praeger Press; 1983. p. 27-49.

12. Lippe BM. Physical and anatomical abnormalities in Turner syndrome. In: Rosenfeld RG, Grumbach MM, editors. Turner syndrome. New York: Marcel Dekker Inc; 1990. pp. 187-204.

13. Rizell S. Dentofacial morphology in Turner syndrome karyotypes. Swed Dent J Suppl. 2012;(225):7-98.

14. Abulwefa A, Brkić H, Kaić Z. Differences in the Eruption Angle of Palatally Displaced Canines in Klinefelter Syndrome: A Retrospective Study on Panoramic Radiographs. Acta Stomatol Croat. 2017;51(4):300-8.

15. Townsend G, Jensen BL, Alvesalo L. Reduced tooth size in $45, X$ (Turner syndrome) females. Am J Phys Anthropol. 1984;65:36771.

16. Alvesalo L, Tammisalo E, Townsend G. Upper central incisor and canine tooth crown size in 47, XXY males. J Dent Res. 1991;70:1057-60.

17. Mayhall JT, Alvesalo L, Townsend GC. Tooth crown size in 46, X, i (Xq) human females. Arch Oral Biol. 1991;36:411-4.

18. Šćepan I, Babić M, Glišić B. Mesiodistal dimension of permanent teeth in men with Klinefelter's syndrome. Eur J Orthod. 1993;15:195-7.

19. Brkić H, Kaić Z, Poje Z, Vitezić-Misjak, M. Increased Size of Tooth Crown in 47, XXY Male. Coll Antropol. 1994;18:113-7.

20. Kaić Z, Bagić I, Poje Z, Dumić M. Gonadal Dysgenesis and Reduction of Teeth Crown Dimensions. Coll Antropol. 1994;18(Sup$\mathrm{pl}): 119-24$.

21. Midtbø M, Halse A. Tooth crown size and morphology in Turner syndrome. Acta Odontol Scand. 1994;52:7-19.

22. Szilágyi A, Keszthelyi G, Nagy G, Madléna M. Oral manifestations of patients with Turner syndrome. Oral Surg Oral Med Oral Pathol Oral Radiol Endod. 2000 May;89(5):577-84.

23. Zilberman U, Smith P, Alvesalo L. Crown components of mandibular molar teeth in 45, X females (Turner syndrome). Arch Oral Biol. 2000 Mar;45(3):217-25.

24. Faggella A, Guadagni MG, Cocchi S, Tagariello T, Piana G. Dental features in patients with Turner syndrome. Eur J Paediatr Dent. 2006 Dec;7(4):165-8

25. Pentinpuro RH, Lähdesmäki RE, Niinimaa AO, Pesonen PR, Alvesalo LJ. Crown heights in the permanent teeth of $45, X$ and $45, X / 46, X X$ females. Acta Odontol Scand. 2014 Nov;72(8):908-16.

26. Keeler C. Taurodont molars and shovel incisors in Klinefelter's syndrome. J Hered. 1973;64:234-6.

27. Maćesić M, Kaić Z, Dumancić J, Poje Z, Dumić M. Occlusal Molar Surfaces in Females with Turner's Syndrome. Coll Antropol. 2003 Dec;27(2):761-8.
28. Nakayama M, Lähdesmäki R, Niinimaa A, Alvesalo L. Molar morphology and the expression of Carabelli's trait in 45, X females. Am J Hum Biol. 2015 Jul-Aug;27(4):486-93.

29. Midtbø M, Halse A. Root length, crown height and root morphology in Turner syndrome. Acta Odontol Scand. 1994;52:303-14.

30. Lähdesmäki R, Alvesalo L. Root growth in the permanent teeth of 45,X/46,XX females. Eur J Orthod. 2006 Aug;28(4):339-44.

31. Lähdesmäki R, Alvesalo L. Root lengths in the permanent teeth of Klinefelter (47,XXY) men. Arch Oral Biol. 2007 Sep;52(9):822-7.

32. Alvesalo L. The expression of human sex chromosome genes in oral and craniofacial growth. In: Scott GR, Irish JD, editors. Anthropological perspectives on tooth morphology: genetics, evolution, variation. Cambridge: Cambridge University Press; 2013. p. 92-107.

33. Komatz Y, Tomoyoshi T, Yoshida O, Fujimoto A, Yoshitake K. Taurodontism and Klinefelter's syndrome. J Med Genet. 1978;15:452-4.

34. Midtb $\varnothing$ M, Halse A. Occlusal morphology in Turner syndrome. Eur J Orthod. 1996;18:103-9.

35. Alvesalo L, Laine T. Occlusion in 47, XXY Klinefelter syndrome men. Am J Hum Genet. 1992;33:464-9.

36. Townsend G, Alvesalo L, Jensen BL, Kari M. Patterns of tooth size in chromosomal aneuploidies. In: Russell DE, Santoro JP, Signogneau-Russell D, editors. Teeth revisited: proceedings of VIlth international symposium on dental morphology). Memoires Series, Paris: Museum National d'Historie Naturelle; 1988. pp. 25-45.

37. Varrela J, Townsend G, Alvesalo L. Tooth crown size in human females with 45, X/46, XX chromosomes. Arch Oral Biol. 1988;33:291-4.

38. Kirveskari P, Alvesalo L. Dental morphology in Turner's syndrome (45, X females). In: Kurten B, editor. Teeth: form, function, and evolution. New York: Columbia University Press; 1982. p. 298-303.

39. Alvesalo L, Tammisalo E. Enamel thickness in 45, X females' permanent teeth. Am J Hum Genet, 1981;33:464-9.

40. Turner II CG, Nichol CR, Scott GR. Scoring Procedures for Key Morphological Traits of the Permanent Dentition: The Arizona State University Dental Anthropology System. In: Kelley MA, Larsen CS, editors. Advances in Dental Anthropology. New York: John Wiley and Sons Inc; 1991. pp. 13-31.

41. Scott GR, Irish JD. Human tooth crown and root morphology: the Arizona State University Dental Anthropology System. Cambridge: Cambridge University Press; 2017. 332 p.

42. Scott GR, Turner CG. The anthropology of modern human teeth: dental morphology and its variation in recent human populations. Cambridge: Cambridge University Press. 1997. 382 p.

43. Scott GR, Turner II CG, Townsend GC, Martinon-Torres M. The anthropology of modern human teeth: dental morphology and its variation in recent and fossil Homo sapiens. 2nd ed. Cambridge: Cambridge University Press. 2018. 396 p.

44. Alvesalo L. Dental growth in 47, XYY males and in conditions with other sex chromosome anomalies. In: Sandberg AA, editor. The $Y$ chromosome, part B, clinical aspects of $Y$ chromosome anomalies. Vol. 6. New York: Alan R. Liss; 1985. pp. 277-300.

45. Alvesalo L, Tammisalo E, Therman E. 47, XXX females, sex chromosomes and tooth crown structure. Hum Genet. 1987;77:345-8.

46. Garn SM, Lewis AB, Kerewsky RS. X-linked inheritance of tooth size. J Dent Res. 1965;44:439-41.

47. Alvesalo L, Kari, M. Sizes of deciduous teeth in 47, XXY males. Am Jum Genet. 1977;29:486-9.

48. Alvesalo L, Portin P. 47, XXY males: Sex chromosomes and tooth size. Am J Hum Genet. 1980; 32: 955-9.

49. Townsend G, Alvesalo L. The size of permanent teeth in Klinefelter (47, XXY) syndrome in man. Arch Oral Biol. 1985;30:83-4.

50. Midtbø M, Halse A. Skeletal maturity, dental maturity, and eruption in young patients with Turner syndrome. Acta Odontol Scand. 1992;50:303-12.

51. Fillipsson R, Lindsten J, Almquist S. Time of eruption of the permanent teeth, cephalometric and tooth measurements and sulphation factor activity in 45 patients with Turner's syndrome with different types of X-chromosome aberration. Acta Endocrinol. 1965;48,:91-113.

52. Kari M, Alvesalo L, Manninen K. Sizes of deciduous teeth in 45, X females. J Dent Res. 1980;59:1382-5.

53. Garn SM. Genetics of tooth development. In: McNamara JA, editor. The biology of occlusal development (Craniofacial growth series). Ann Arbor, MI: Center for Human Growth and Development, University of Michigan; 1977. pp. 61-88. 
54. Garn SM, Dahlberg AA, Lewis AB, Kerewsky RS. Groove pattern, cusp number, and tooth size. J Dent Res. 1966;45(3):970.

55. Garn SM, Dahlberg AA, Lewis AB, Kerewsky RS. Interaction between relative molar size and relative number of cusps. J Dent Res. 1966;45(4):1240.

56. Harris EF. Carabelli's trait and tooth size of human maxillary first molars. Am J Phys Anthropol. 2007 Feb;132(2):238-46.

57. Keene HJ. The relationship between Carabelli's trait and the size, number, and morphology of the maxillary molars. Arch Oral Biol. 1968;13:1023-5.

58. Kieser JA, Becker PJ. Correlations of dimensional and discrete dental traits in the post-canine and anterior dental segments. J Dent Assoc S Afr. 1989;44:101-3.

59. Kondo S, Townsend GC. Associations between Carabelli's trait and cusp areas in human permanent maxillary first molars. Am J Phys Anthropol. 2006 Feb;129(2):196-203.

60. Lombardi AV. Tooth size associations of three morphologic dental traits in a Melanesian population. J Dent Res. 1975;54:239-43.

61. Reid C, van Reenen JF, Groenveld HT. Tooth size and the Carabelli trait. Am J Phys Anthropol. 1991;84:427-32.

62. Reid C, van Reenen JF, Groenveld HT. The Carabelli trait and maxillary molar cusp and crown base areas. In: Smith P, Tchernov $E$, editors. Structure, function, and evolution of teeth. London: Freund; 1992. p. 451-466.

63. Scott GR. Lingual tubercles and the maxillary incisor-canine field. J Dent Res. 1977;56: 1192.

64. Scott GR. Interaction between shoveling of the maxillary and mandibular incisors. J Dent Res. 1977;56:1423.

65. Scott GR. Association between the hypocone and Carabelli's trait of the maxillary molars. J Dent Res. 1979;58:1403-4.

66. Turner II CG. Directionality in the canine field model. J Dent Res. 1969;48:1310.

67. Keene HJ. The relationship between third molar agenesis and the morphologic variability of the molar teeth. Angle Orthod. 1965;35:289-98.

68. Nakayama M, Kondo O, Pesonen P, Alvesalo L, Lähdesmäki R. Influence of long and short arms of $X$ chromosome on maxillary molar crown morphology. PLoS One. 2018 Nov 15;13(11):e0207070.
69. Jernvall J, Kettunen P, Karavanova I, Martin LB, Thesleff I. Evidence for the role of the enamel knot as a control center in mammalian tooth cusp formation: non-dividing cells express growth stimulating Fgf-4 gene. Int J Dev Biol. 1994 Sep;38(3):463-9.

70. Jernvall J, Thesleff I. Tooth shape formation and tooth renewal: evolving with the same signals. Development. 2012;139:348797.

71. Luukko K, Loes S, Furmanek T, Fjeld K, Kvinnsland IH, Kettunnen $P$. Identification of a novel putative signaling center, the tertiary enamel knot in the postnatal mouse molar tooth. Mech Dev. 2003 Mar;120(3):270-6.

72. Thesleff I. The developmental anatomy of teeth. In: Baldock R, Bard J, Davidson D, Morriss-Kay G, editors. Kaufman's atlas of mouse development supplement. Cambridge, MA: Academic Press; 2016. p. 231-8.

73. Jernvall J, Jung HS. Genotype, phenotype, and developmen tal biology of molar tooth characters. Am J Phys Anthropol. 2000;113(S31):171-90.

74. Kettunen P, Thesleff I. Expression and function of FGFs-4, -8, and -9 suggest functional redundancy and repetitive use as epithelial signals during tooth morphogenesis. Dev Dyn. 1998;211:256-68.

75. Thesleff I. Developmental biology and building a tooth. Quintessence Int. 2003 Sep;34(8):613-20.

76. Plikus MV, Zeichner-David M, Mayer JA, Reyna J, Bringas P, Thewissen JG, et al. Morphoregulation of teeth: Modulating the number, size, shape, and differentiation by tuning Bmp activity. Evol Dev. 2005 Sep-Oct;7(5):440-57.

77. Kassai Y, Munne P, Hotta Y, Penttila E, Kavanagh K, Ohbayashi N, et al. Regulation of mammalian tooth cusp patterning by ectodin. Science. 2005 Sep 23;309(5743):2067-70.

78. Mayhall J, Alvesalo L. Molar crown trait expression in individuals with sex chromosome anomalies. J Dent Res 1988;67:116. Abs no 27.

79. Scott GR, Anta A, Schomberg R, de la Rúa C. Basque dental morphology and the 'Eurodont' dental pattern. In: Scott GR, Irish JD, editors. Anthropological Perspectives on Tooth Morphology: Genetics, Evolution, Variation. Cambridge: Cambridge University Press; 2013. p. 296-318. 